\title{
Plasma Levels of Pre $\beta 1-H D L$ Are Significantly Elevated in Non-Dialyzed Patients with Advanced Stages of Chronic Kidney Disease
}

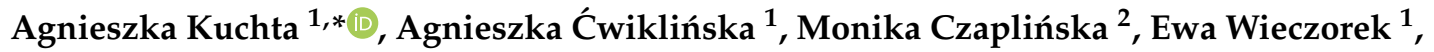 \\ Barbara Kortas-Stempak ${ }^{1}$, Anna Gliwińska ${ }^{1}$, Kamil Dąbkowski ${ }^{1}$, Kornelia Sałaga-Zaleska ${ }^{1}$, \\ Agnieszka Mickiewicz ${ }^{3}$, Alicja Dębska-Ślizień ${ }^{2}$, Ewa Król ${ }^{2}$ () and Maciej Jankowski ${ }^{1,4}$ (1) \\ 1 Department of Clinical Chemistry, Medical University of Gdańsk, 80-210 Gdańsk, Poland; \\ agnieszka.cwiklinska@gumed.edu.pl (A.Ć.); ewa.wieczorek@gumed.edu.pl (E.W.); \\ barbara.kortas-stempak@gumed.edu.pl (B.K.-S.); anna.gliwinska@gumed.edu.pl (A.G.); \\ kamil.dabkowski@gumed.edu.pl (K.D.); kornelia.salaga-zaleska@gumed.edu.pl (K.S.-Z.); \\ maciej.jankowski@gumed.edu.pl (M.J.) \\ 2 Clinic \& Chair of Nephrology, Transplantology and Internal Diseases, Medical University of Gdańsk, \\ 80-210 Gdańsk, Poland; monika.czaplinska@gumed.edu.pl (M.C.); \\ alicja.debska-slizien@gumed.edu.pl (A.D.-Ś.); ewa.krol@gumed.edu.pl (E.K.) \\ 3 1st Department of Cardiology, Medical University of Gdańsk, 80-210 Gdańsk, Poland; \\ agnieszka.mickiewicz@gumed.edu.pl \\ 4 Laboratory of Molecular and Cellular Nephrology, Mossakowski Medical Research Centre Polish Academy \\ of Sciences, 80-210 Gdańsk, Poland \\ * Correspondence: agakuchta@gumed.edu.pl; Tel.: +48-583492795
}

Received: 7 February 2019; Accepted: 6 March 2019; Published: 9 March 2019

\begin{abstract}
In chronic kidney disease (CKD), the level of high-density lipoprotein (HDL) decreases markedly, but there is no strong inverse relationship between HDL-cholesterol (HDL-C) and cardiovascular diseases. This indicates that not only the HDL-C level, but also the other quantitative changes in the HDL particles can influence the protective functionality of these particles, and can play a key role in the increase of cardiovascular risk in CKD patients. The aim of the present study was the evaluation of the parameters that may give additional information about the HDL particles in the course of progressing CKD. For this purpose, we analyzed the concentrations of HDL containing apolipoprotein A-I without apolipoprotein A-II (LpA-I), pre $\beta 1-H D L$, and myeloperoxidase (MPO), and the activity of paraoxonase-1 (PON-1) in 68 patients at various stages of CKD. The concentration of HDL cholesterol, MPO, PON-1, and lecithin-cholesterol acyltransferase (LCAT) activity were similar in all of the analyzed stages of CKD. We did not notice significant changes in the LpA-I concentrations in the following stages of CKD (3a CKD stage: $57 \pm 19$; 3b CKD stage: $54 \pm 15$; 4 CKD stage: $52 \pm 14 ; p=0.49$ ). We found, however, that the pre $\beta 1-H D L$ concentration and preß1-HDL/LpA-I ratio increased along with the progress of CKD, and were inversely correlated with the estimated glomerular filtration rate (eGFR), even after adjusting for age, gender, triacylglycerols (TAG), HDL cholesterol, and statin therapy ( $\beta=-0.41, p<0.001 ; \beta=-0.33, p=0.001$, respectively). Our results support the earlier hypothesis that kidney disease leads to the modification of HDL particles, and show that the preß1-HDL concentration is significantly elevated in non-dialyzed patients with advanced stages of CKD.
\end{abstract}

Keywords: high-density lipoproteins; chronic kidney disease; atherosclerosis 


\section{Introduction}

A number of studies have shown that chronic kidney disease (CKD) is associated with high cardiovascular mortality as a result of accelerated atherosclerosis. An increased predisposition to atherosclerosis is largely driven by chronic inflammation, oxidative stress, and dyslipidaemia, which are usually associated with CKD [1-3]. The dyslipidemia of CKD patients is classically characterized by hypertriglyceridemia and a low concentration of high-density lipoprotein cholesterol (HDL-C) associated with normal or slightly reduced low-density lipoprotein cholesterol (LDL-C) levels $[4,5]$. Notably, although the serum HDL-C concentration exhibits a strong inverse association with cardiovascular disease in the general population, this association is attenuated and eventually abrogated as the kidney disease progresses [6]. This suggests that not only the cholesterol level of HDLs, but also the quality modification in HDL particles, may be crucial for the increase of cardiovascular risk in CKD patients. Several previous studies have shown that renal disorders may modify the concentrations of apolipoproteins, lipid transfer proteins, and enzymes connected with HDL particles, which may directly affect their biogenesis maturation, catabolism, and biological activity $[7,8]$. HDL represents a heterogeneous class of lipoproteins, whose particles may differ in composition and function. Because of the important role of apolipoproteins in maturation, metabolism, and functionality, the HDL particles are divided into those that do not contain apolipoprotein A-II (LpA-I) and those that contain the two main apolipoproteins, A-I and A-II (LpA-I/ A-II).

Some clinical studies have suggested better athero-protective properties of LpA-I particles, although not all trials have supported these observations [9-11]. LpA-I, despite its apparent homogenous main apolipoprotein composition, is still a heterogeneous fraction, and its subfractions may differ both in size, density, and potentially in their antiatherogenic effects. One of the LpA-I subfractions - which, in recent years, has been of particular interest because of its important role in reverse cholesterol transport-is the preß1-HDL fraction. Despite the fact that preß1-HDL is known as an initial plasma acceptor of cell-derived cholesterol and plays an important role in the first step of reserve cholesterol transport, previous studies have shown the elevation of this HDL subfraction in patients with coronary artery disease, which may be connected with the delayed maturation of preß1-HDL or its enhanced production [12,13]. A significant increase of the preß1-HDL fraction was also observed in hemodialysis patients [14], but the data about non-dialysis patients are scarce.

Under normal circumstances, HDL particles protect against atherosclerosis through reverse cholesterol transport, but they also behave as an anti-oxidant, removing oxidant molecules from the arterial wall and limiting the oxidative modification of LDL [15]. CKD is a pathological state associated with the impaired antioxidative activity of HDL particles, possibly due to the reduced activity of HDL-associated enzymes, such as paraoxonase 1 (PON-1) and lecithin-cholesterol acyltransferase (LCAT). One of the potential pathways of losing the biological activity by HDL particles in CKD is an increase in myeloperosidase (MPO) activity in the course of the atherosclerotic processes in the wall of the human artery $[16,17]$.

The aim of the present study was the evaluation of the parameters that may give additional information about HDL particles in the course of progressing CKD. For this purpose, we analysed the concentrations of LpA-I, preß1-HDL, and MPO, and the activity of PON-1 and LCAT, in non-dialysis patients at various stages of CKD. In addition, we tested whether statin therapy has a significant impact on the qualitative and quantitative change of HDL subfractions.

\section{Results}

The clinical characteristics of the patients at various stages of CKD are shown in Table 1. The analyzed groups did not differ in their average age, sex, and body mass index (BMI) index. The concentrations of HDL-C were similar in all of the analyzed stages of chronic kidney disease. The changes in the concentrations of triacylglycerols (TAG), total cholesterol (TC), and LDL-C were also insignificant between the study groups. The HDL particles from the patients at various stages of CKD did not differ in the concentrations of their main proteins-apolipoprotein A-I (ApoA-I) and 
apolipoprotein A-II (ApoA-II) (Table 1). The concentration of the HDL subpopulation containing apoA-I without apoA-II (LpA-I) decreased slightly in the following stages of CKD, but the changes were insignificant (Figure 1A). There was also no significant correlation between the LpA-I levels and the estimated glomerular filtration rate (eGFR) (Table 2). However, an analysis of the preß1-HDL fraction showed its remarkable increase along with the progression of CKD (Figure 1B). The share of preß1-HDL in the LpA-I fraction also increased significantly in the following stage of CKD (Figure 1C).

Table 1. Characteristics of patients at various stages of chronic kidney disease (CKD).

\begin{tabular}{ccccc}
\hline Parameter & \multicolumn{5}{c}{ Stages of CKD } \\
\hline & 3a & 3b & $\mathbf{4}$ & $p$-Value \\
\hline Gender (M/F) & $12 / 5$ & $19 / 15$ & $12 / 5$ & $0.531^{* *}$ \\
Age (years) & $69 \pm 5$ & $70 \pm 9$ & $63 \pm 5$ & $0.06^{*}$ \\
BMI (kg/m $\left.{ }^{2}\right)$ & $28 \pm 3$ & $29 \pm 5$ & $26 \pm 4$ & $0.306^{*}$ \\
eGFR & $50 \pm 3$ & $37 \pm 4$ & $22 \pm 4$ & $<0.001^{*}$ \\
Albumin (g/L) & $43.6 \pm 3.2$ & $42.8 \pm 2.9$ & $42.9 \pm 2.9$ & $0.674^{*}$ \\
Statin therapy $\%$ ) & 41 & 53 & 64 & $0.333^{* *}$ \\
TAG (mg/dL) & $102 \pm 30$ & $117 \pm 45$ & $135 \pm 63$ & $0.215^{*}$ \\
TC (mg/dL) & $199 \pm 42$ & $200 \pm 53$ & $215 \pm 36$ & $0.345^{*}$ \\
HDL-C (mg/dL) & $51 \pm 11$ & $50 \pm 12$ & $48 \pm 11$ & $0.761^{*}$ \\
LDL-C (mg/dL) & $127 \pm 39$ & $127 \pm 49$ & $140 \pm 33$ & $0.335^{*}$ \\
ApoA-I (mg/dL) & $172 \pm 27$ & $164 \pm 27$ & $160 \pm 23$ & $0.297^{*}$ \\
ApoA-II (mg/dL) & $33 \pm 7$ & $31 \pm 6$ & $31 \pm 5$ & $0.499^{*}$ \\
LCAT (390/470 nm) & $1.34 \pm 0.03$ & $1.32 \pm 0.05$ & $1.32 \pm 0.04$ & $0.458^{*}$ \\
FC/TC & $0.283 \pm 0.05$ & $0.283 \pm 0.03$ & $0.290 \pm 0.03$ & $0.234^{*}$ \\
\hline
\end{tabular}

Continuous values are presented as means \pm standard deviation (SD). Potential differences among the results were analysed using analysis of variance (ANOVA) * or the Pearson's chi-squared test ${ }^{* *}$. BMI—body mass index; eGFR - estimated glomerular filtration rate; TAG-triacylglycerols; TC-total cholesterol; HDL-C—high-density lipoprotein cholesterol; LDL-C—low-density lipoprotein cholesterol; ApoA-I—apolipoprotein A-I; ApoA-II-apolipoprotein A-II; LCAT-lecithin-cholesterol acyltransferase; FC/TC—free cholesterol/total cholesterol ratio.
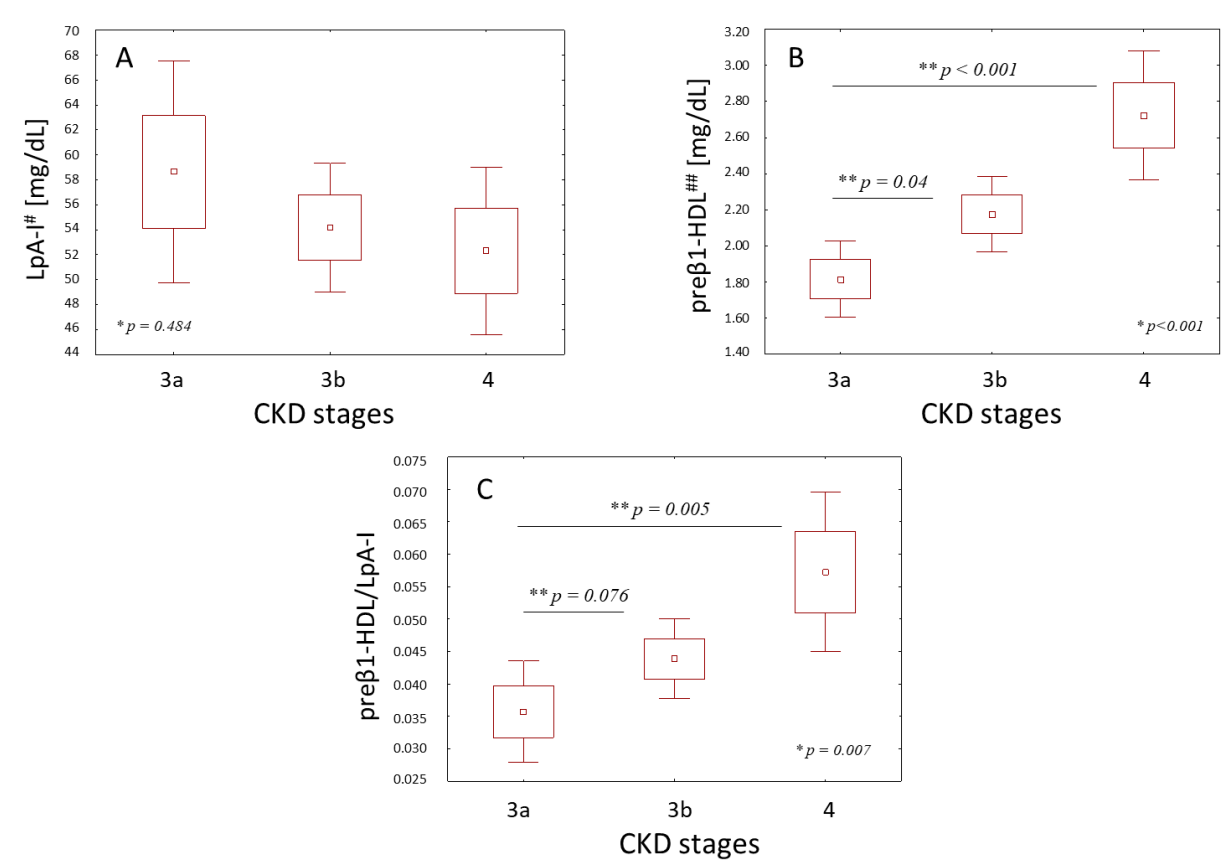

Figure 1. HDL containing apolipoprotein A-I without apolipoprotein A-II (LpA-I) (A), the preß1-high-density lipoprotein (HDL) (B) concentrations, and the preß1-HDL/LpA-I (C) values in the various stages of chronic kidney disease (CKD). Values are presented as mean \pm standard error (SE) (2 SE) and were assessed using the analysis of variance (ANOVA) test * with the Tukey's post-hoc test ${ }^{* *}$ to determine where the differences existed; " ApoA-I content of LPAI; ${ }^{\# \#}$ ApoA-I content of preß1-HDL. 
Table 2. Univariate correlation between HDL-related parameters and eGFR.

\begin{tabular}{ccc}
\cline { 2 - 3 } Parameter & $\mathbf{R}$ & $p$ \\
\cline { 2 - 4 } HDL-C $(\mathrm{mg} / \mathrm{dL})$ & 0.104 & 0.382 \\
ApoA-I $(\mathrm{mg} / \mathrm{dL})$ & 0.153 & 0.202 \\
ApoA-II $(\mathrm{mg} / \mathrm{dL})$ & 0.109 & 0.358 \\
LpA-I $(\mathrm{mg} / \mathrm{dL})$ & 0.025 & 0.837 \\
pre $\beta 1-\mathrm{HDL}(\mathrm{mg} / \mathrm{dL})$ & -0.456 & $<0.001$ \\
pre$\beta 1-\mathrm{HDL} / \mathrm{LpA}-\mathrm{I}$ & -0.322 & 0.008 \\
PON-1 (U/L) & 0.068 & 0.566 \\
MPO (ng/mL) & 0.079 & 0.531 \\
LCAT (390/470 nm) & 0.080 & 0.484 \\
R-Spearman's correlation coefficient. PON-1-paraoxonase-1; MPO-myeloperoxidase.
\end{tabular}

The univariate correlation analysis indicated that the preß1-HDL concentration and preß1-HDL/LpA-I ratio were inversely correlated with the severity of the CKD expressed by eGFR (Table 2), and remained an independent determinant of the CKD severity in the multiple linear regression after adjusting for age, gender, TAG, HDL-C, and statin therapy (Table 3).

Table 3. Multiple linear regression analysis for the eGFR value *.

\begin{tabular}{cccc}
\hline Parameter & $\boldsymbol{\beta}$ & $\mathrm{SE}$ & $\boldsymbol{p}$ \\
\hline pre $\beta 1-\mathrm{HDL}$ & -0.41 & 0.105 & $<0.001$ \\
pre $\beta 1-\mathrm{HDL} / \mathrm{LpA}-\mathrm{I}$ & -0.33 & 0.09 & 0.001 \\
\hline
\end{tabular}

$\beta$ standardized beta coefficients; SE-standard error; * adjusted for age, gender, statin therapy, HDL-C, and TAG concentration.

The activity of LCAT was similar in all of the analyzed stages of chronic kidney disease (Table 1 ), and there were no significant correlations between LCAT activity and pre $\beta 1-\mathrm{HDL}(\mathrm{R}=-0.05 ; p=0.968)$ or LpA-I concentration ( $\mathrm{R}=0.233 ; p=0.062)$. No significant differences in the free cholesterol/total cholesterol ratio (FC/TC) in the course of the progression of CKD were also observed (Table 1).

As shown in Table 4, the authors did not observe a significant change in the PON-1 activity and MPO concentration in the following stages of CKD. The levels of both enzymes were also not correlated with each other $(\mathrm{R}=-0.57 ; p=0.647)$.

Table 4. Activity of paraoxonase-1 (PON-1) and myeloperoxidase (MPO) concentration.

\begin{tabular}{ccccc}
\hline & \multicolumn{4}{c}{ Stages of CKD } \\
\cline { 2 - 5 } & 3a & 3b & $\mathbf{4}$ & $\boldsymbol{p}$-Value * \\
\hline PON-1 (U/L) & $102(53-150)$ & $83(52-152)$ & $113(80-130)$ & 0.890 \\
$\mathrm{MPO}(\mathrm{ng} / \mathrm{mL})$ & $235(136-392)$ & $199(139-347)$ & $273(160-327)$ & 0.377 \\
\hline
\end{tabular}

Values are presented as median (25th and 75th percentiles); ${ }^{*}$ differences among the results were analyzed using the Kruskal-Wallis test.

In the study groups, the statins were being taken by $41 \%$ (15\% Atorvastatin (A.), $21 \%$ Simvastatin (S.), and 3\% Rosuvastatin (R.)), 53\% (35\% A., 15\% S., and 3\% R.), and 64\% (29\% A. and 35\% S.) of the patients in CKD stage $3 \mathrm{a}, 3 \mathrm{~b}$, and 4, respectively. We did not observe significant differences in the concentrations of HDL-C, apoA-I, apoA-II, and LCAT, and in the unesterified/total cholesterol ratio between the patients taking and not taking statins. Statins therapy has also no significant effect on the LpA-I, pre $\beta 1-H D L$ concentration, and preß1-HDL/LpA-I ratio. However, we noted a tendency of a higher concentration of LpA-I, with a lower concentration of preß1-HDL and preß1-HDL/LpA-I ratio in the patients receiving statins in each of the analyzed groups of patients (Figure 2). Simultaneously, the significant differences in the pre $\beta 1$-HDL concentration among the groups were maintained both in the patients receiving statins $(p=0.01)$ and those not receiving this drug $(p=0.005)$. 

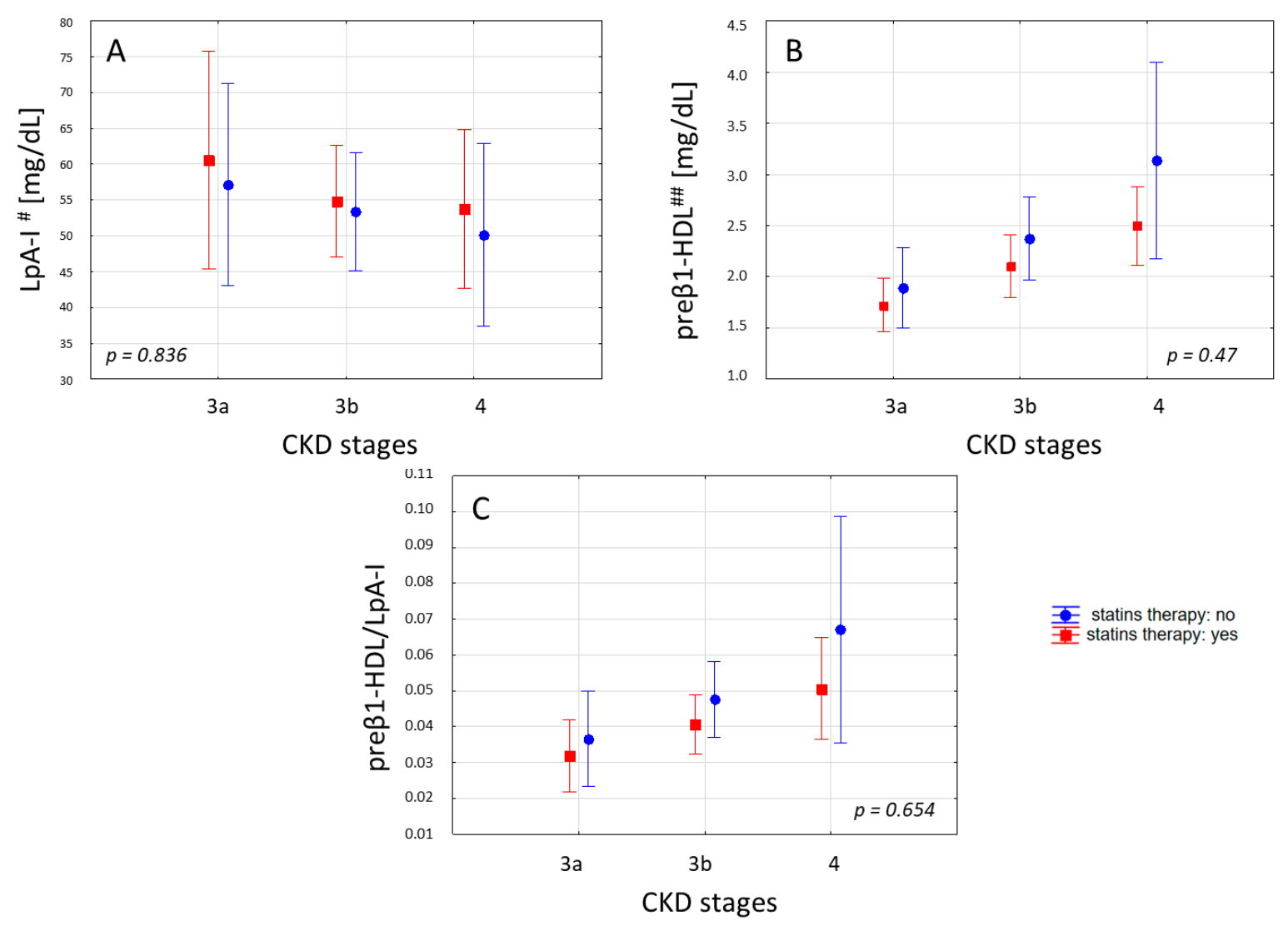

statins therapy: no statins therapy: yes

Figure 2. LpA-I (A), the preß1-HDL (B) concentrations, and the preß1-HDL/ LpA-I (C) values in the patients at various stages of CKD with and without statins therapy. Values are presented as mean $\pm 1.96 \mathrm{SE}$, and were assessed using the ANOVA test. " ApoA-I content of LPAI; \#\# ApoA-I content of preß1-HDL.

\section{Discussion}

The major finding of our study is the demonstration that the pre $\beta 1-H D L$ concentration increases in the 3a-4 stages of CKD. CKD is an independent cardiovascular risk factor, and the gradual decrease of eGFR in CKD patients translates into a linear increase of cardiovascular disease (CVD) mortality [18]. A number of clinical studies showed the increase of pre $\beta 1-H D L$ in patients with coronary artery disease, confirming the associations between increased levels of pre-pre $\beta 1-\mathrm{HDL}$ and the risk of CAD, and proposed that high levels of pre $\beta 1$-HDL remained a significant predictor of CVD even after adjustment for traditional risk factors [19-21]. Despite such an integrating role of the smallest HDL fraction in the atherosclerosis, the data about preß1-HDL in non-dialysis patients with CKD are poor. Midda et al. [14] showed, however, a significant increase of pre $\beta 1-H D L$ in hemodialysis patients, and connected it with an impaired LCAT dependent conversion of pre $\beta 1$-HDL to $\alpha$-migrating HDL. Other clinical and experimental studies have also shown that CKD reduces the levels and activity of circulating LCAT, and down regulates the hepatic LCAT gene expression, especially in the advanced stages of the disease $[22,23]$.

In a physiological condition, LCAT converts pre $\beta 1-H D L$ to $\alpha$-migrating HDL, which transports the esterified cellular cholesterol to the liver for further processing. The impaired LCAT dependent catabolism of lipid poor HDL might be one of the reasons for the increased preß1-HDL in patients with CKD. However, in our study, the change in LCAT activity along the progress of kidney disease was not significant. The FC/TC ratio, which confirms LCAT activity, was also invariable in the course of progressing CKD. We also did not observe any significant correlation between LCAT activity and pre $\beta 1-\mathrm{HDL}$ concentration, which may suggest that the mechanism of the increase of pre $\beta 1-\mathrm{HDL}$ 
levels in non-hemodialysis CKD patients might be complex and not only dependent on LCAT activity. The kidney is a major site of HDL homeostasis. Impaired renal catabolism of the immature small HDL particles may be another cause of preß1-HDL elevation in patients with renal disorders. Additionally, as mentioned earlier, the elevation of the triglyceride-rich lipoprotein is typical for dyslipidemia in CKD. This induces the transfer of excess triglyceride into HDL particles and intensifies the conversion of $\alpha$-migrating HDL to pre $\beta 1-H D L$ by cholesteryl ester transfer protein (CETP) activity. However, the multiple linear regression shows that the preß1-HDL values remained an independent determinant of chronic kidney severity even after adjusting for TAG, age, gender, HDL cholesterol, and statin therapy (Table 3), which may confirm the hypothesis that the progressive disturbances in the HDL metabolism are one of the reasons for accelerated atherosclerosis in CKD patients. Some previous studies have suggested that the quantification of HDL particles containing ApoA-I without ApoA-II (LpA-I) could provide additional information in predicting coronary artery disease in the general population, although not all trials have supported this hypothesis [24]. To date, only a few studies have reported about the quantification of LpA-I in patients affected by renal disorders. Decreased levels of LpA-I were found in patients on continuous ambulatory peritoneal dialysis [25], however there are no data about LpA-I particles in non-dialysis patients. In our study, LpA-I decreased slightly in the following stages of $C K D$, but the change was insignificant (Figure 1A). There was also no significant correlation between LpA-I levels and the severity of kidney disease expressed by GFR (Table 2). When analyzing the share of preß1-HDL in the LpA-I fraction, we show a clear increase of relative preß1-HDL/LpA-I values as the GFR decreases (Figure 1C). These results suggest that renal disorders affect the distribution of HDL subfractions, and seem to be consistent with our earlier work in which we have shown that the distribution of LpA-I is different in patients with coronary artery disease [19]. However further research is required in order to test whether the observed quantitative changes in the HDL fractions reflect the dysfunctions of the functional proprieties of HDL particles in CKD patients.

Normal HDL particles possess potent antioxidant and anti-inflammatory properties that are as critical for protection against atherosclerosis as its role in reserve cholesterol transport. The antioxidant and anti-inflammatory properties of HDL are mediated, among others, by its constituent antioxidant enzyme-paraoxonase-1 (PON-1). PON-1 activity is an essential mechanism, by which HDL inhibits LDL oxidation. This enzyme hydrolyzes aromatic carboxylic acid esters, organophosphates, and oxidized phospholipids, simultaneously destroying biologically active lipids in mildly oxidized lipoproteins, thus protecting them against further oxidation [26]. CKD is a pathological state that alters the anti-oxidative and anti-inflammatory activity of HDL particles $[27,28]$. One of the potential pathways of converting an antiatherogenic HDL into its atherogenic forms in CKD involves a disturbance in the PON-1 activity caused by the pro-oxidant activity of myeloperoxidase (MPO) [28]. Growing evidence in the literature underscores the impact of the serum PON1 and MPO activity on the development of atherosclerotic changes in CKD patients [29,30].

In our study, we observed no significant change in the PON-1 and MPO activity along the progress of kidney disorders (Table 4). The activities of the enzymes were also not correlated with each other. However, an analysis of the earlier studies shows that significant changes in the activity of PON-1 and MPO appear most often in the end stages of chronic kidney disease [31,32], which may explain the lack of significance in our moderately advanced group of patients with CKD.

Of the patients, $51 \%$ had to undergo statin therapy in our study group. The importance of statin therapy in chronic kidney disease is not obvious. On the one hand, statins are generally considered to be effective in retarding CKD progression and reducing cardiovascular complication in patients with mild to moderate renal disease $[5,33]$. On the other hand, large clinical trials have failed to improve outcomes in patients with the end stage of the disease or maintenance dialysis [34-36].

The impact of statins on LpA-I subpopulations also remains in question. Some clinical studies have shown that statins decrease small pre $\beta 1-\mathrm{HDL}$ and increase the concentration of the cholesterol-rich LpA-I fraction $[25,37]$. This effect is probably related to the inhibitory effect of statins on the activity of 
CETP, as well as the consequence of the lower number of lipoproteins available, sending triglyceride molecules in exchange for cholesterol from HDL. However not all clinical studies have shown that statins have a positive cardiovascular effect with more rapid maturation of small preß1-HDL into cholesterol-rich $\alpha$ HDL $[38,39]$. In our study, we did not notice the significant impact of statin therapy on concentrations of LpA-I or pre $\beta 1-H D L$. We observed only the tendency of a higher concentration of LpA-I and a lower concentration of pre $\beta 1-\mathrm{HDL}$ in the patients receiving statins in the following stage of CKD, which maintained the significant differences in the preß1-HDL concentration among the groups of the following CKD stages-both in the patients receiving statins and those not receiving this drug. However, considering the number of patients in our study groups, the influence of statins on the quantitative changes in the HDL factions requires a larger, and better matched, in terms of therapy, group of patients.

In conclusion, our results support an earlier hypothesis, that CKD leads to quantitative modification of HDL particles. The plasma levels of preß1-HDL are significantly elevated in non-dialyzed patients with advanced stages of CKD. Further research is required in order to establish whether the preß1-HDL concentration can serve as a biomarker of HDL quality, which can be used in the risk stratification and prognosis of cardiovascular complications in patients with CKD.

\section{Materials and Methods}

\subsection{Subjects}

Sixty-eight non-dialysis, adult patients from the Outpatient Clinic of the Nephrology Department of the Medical University of Gdańsk, in CKD stages 3a: GFR of 45-59; 3b: GFR of 30-44; and 4: GFR of $15-30 \mathrm{~mL} / \mathrm{min} / 1.73 \mathrm{~m}^{2}$, according to the four-parameter Modification of Diet in Renal Disease (MDRD 4-p) formula, were recruited into the study. The exclusion criteria were as follows: diabetes, proteinuruia in dipstick test and hypalbuminemia, liver diseases, malignancy, treatment with immunosuppressive agents, fibrates, or heparin preparations of acute diseases within three months before the study. The patients received the following statins: Atorvastatin (A.), Simvastatin (S.), and Rosuvastatin (R.), or they did not receive a lipid-lowering therapy. The study was performed in accordance with the ethical guidelines of the 1975 Declaration of Helsinki and was approved by the Medical Ethics Committee of the Medical University of Gdańsk (Project code: NKBBN/541/2014-2015; approved on 02 February2015). All of the participants provided written informed consent.

\subsection{Laboratory Measurements}

Blood samples were obtained between 07:00 and 08:00 following an overnight fast. The samples (serum or plasma) were separated after centrifugation at $1000 \times \mathrm{g}$ for $15 \mathrm{~min}$, and were stored at $-80^{\circ} \mathrm{C}$ pending analysis. For the preß1-HDL test, we used plasma with edetic acid (EDTA). Immediately after sample collection, the blood was kept on ice and centrifuged within $15 \mathrm{~min}$ in ordr to separate the plasma, which was immediately diluted 21 -fold with the stabilization buffer ( $50 \%$ sucrose and $0.05 \%$ NaN3). The stabilized sample was then stored at $-80^{\circ} \mathrm{C}$. The total cholesterol (TC) and triacylglycerols (TAG) were measured using commercially available enzymatic kits obtained from Pointe Scientific (Warsaw, Poland). The free cholesterol (FC) was measured using an enzymatic kit obtained from Greiner Laboratories (Flacht, Germany).

The HDL was isolated by the precipitation of apolipoprotein B-containing lipoproteins with heparin and manganese chloride, and the HDL-cholesterol (HDL-C) was measured in supernatant using a kit obtained from Pointe Scientific. The LDL-cholesterol (LDL-C) level was calculated using the Friedewald formula.

The serum albumin was measured using the bromocresol green dye-binding method (Pointe Scientific). The ApoA-I and ApoA-II serum concentrations were determined using the nephelometric method with antibodies obtained from Siemens Healthcare Diagnostics (Escgborn, Germany) on a 
Behring laser nephelometer. The LPA-I concentration (ApoA-I content of LPA-I) was assayed using an electroimmunodiffusion technique (Hydragel LpAI, Sebia, Lisses, France).

The preß1-HDL levels (ApoA-I content of preß1-HDL) were measured according to a previously described method [40] by an enzyme immunoassay (preß1-HDL ELISA; Sekisui Diagnostics, Lexington, MA, USA), which uses a mouse anti-human pre $\beta 1-H D L$ monoclonal antibody (MAb 55201) and a goat anti-human apoA-I polyclonal antibody. The LCAT activity was measured in the plasma using a commercial kit (MAK107-1KT, Sigma-Aldrich, Saint Luis, MO, USA), where the enzyme activity was evaluated as a ratio change of the fluorescence intensity of the substrate at 390 to $470 \mathrm{~nm}$. The total paraoxonase- 1 activity was measured in a serum with paraoxon ethyl as the substrate, according to the procedure described earlier [41]. Mieloperoxidase was analyzed in the plasma using an enzyme immunoassay kit (MPO ELISA; Immundiagnostik Bensheim, Gemany).

\subsection{Statistics}

The statistical analyses were performed using STATISTICA software, version 10 (StatSoft, Kraków, Poland). The Shapiro-Wilk test was used to test the determined normality of the distribution of variables. The continuous variables were expressed as mean \pm SD (standard deviation), or as medians with 25th and 75th percentiles. The ANOVA or Kruskal-Wallis test were used to assess the differences between the groups with an appropriate post hoc test to determine exactly where the difference is significant. The Pearson's chi-squared test was used to compare categorical variables. Univariate correlations were assessed using standardized Spearman coefficients. Multilinear regression was assessed using standardized $\beta$ coefficients. P values below 0.05 were considered to be statistically significant.

Author Contributions: Conceptualization, A.K., A.Ć., and M.C.; methodology, A.Ć. and B.K.; software, A.G.; validation, A.Ć. and B.K.-S.; formal analysis, A.K. and A.Ć.; investigation, E.W., K.D., and K.S.-Z.; resources, M.C., A.D.-Ś., and E.K.; data curation, M.C.; writing (original draft preparation): A.K. and A.Ć; writing (review and editing), A.M., A.D.-Ś., and M.J., visualization: A.M. and M.C.; supervision, M.J. and E.K.; project administration, A.K.; funding acquisition, A.K., M.J., and A.D.-Ś.

Funding: This work was supported by the Medical University of Gdańsk, under grants no. MN 01-0217/08/524, no. ST 02-0125/07/524, and no. ST 02-0004/07/122.

Conflicts of Interest: The authors declare no conflict of interest.

\section{References}

1. Go, A.S.; Chertow, G.M.; Fan, D.; McCulloch, C.E.; Hsu, C.Y. Chronic kidney disease and the risks of death, cardiovascular events, and hospitalization. N. Engl. J. Med. 2004, 13, 1296-1305. [CrossRef] [PubMed]

2. Gluba-Brzozka, A.; Michalska-Kasiczak, M.; Franczyk-Skora, B.; Nocun, M.; Banach, M.; Rysz, J. Markers of increased cardiovascular risk in patients with chronic kidney disease. Lipids Health Dis. 2014, 13, 135. [CrossRef] [PubMed]

3. Gronda, E.; Genovese, S.; Padeletti, L.; Cacciatore, F.; Vitale, D.F.; Bragato, R.; Innocenti, L.; Schiano, C.; Sommese, L.; De Pascale, M.R.; et al. Renal function impairment predicts mortality in patients with chronic heart failure treated with resynchronization therapy. Cardiol. J. 2015, 4, 459-466. [CrossRef] [PubMed]

4. Vaziri, N.D.; Navab, M.; Fogelman, A.M. HDL metabolism and activity in chronic kidney disease. Nat. Rev. Nephrol. 2010, 5, 287-296. [CrossRef] [PubMed]

5. Reiss, A.B.; Voloshyna, I.; DeLeon, J.; Miyawaki, N.; Mattana, J. Cholesterol Metabolism in CKD. Am. J. Kidney Dis. Off. J. Natl. Kidney Found. 2015, 6, 1071-1082. [CrossRef] [PubMed]

6. Moradi, H.; Vaziri, N.D.; Said, H.M.; Kalantar-Zadeh, K. Role of HDL dysfunction in end-stage renal disease: A doubl-edeged sword. J. Ren. Nutr. Off. J. Council Ren. Nutr. Natl. Kidney Found. 2013, 3, 203-206. [CrossRef] [PubMed]

7. Mangé, A.; Goux, A.; Badiou, S.; Patrier, L.; Canaud, B.; Maudelonde, T.; Cristol, J.-P.; Solassol, J. HDL Proteome in Hemodialysis Patients: A Quantitative Nanoflow Liquid Chromatography-Tandem Mass Spectrometry Approach. PLoS ONE 2012, 3, e34107. [CrossRef] [PubMed] 
8. Holzer, M.; Birner-Gruenberger, R.; Stojakovic, T.; El-Gamal, D.; Binder, V.; Wadsack, C.; Heinemann, A.; Marsche, G. Uremia Alters HDL Composition and Function. J. Am. Soc. Nephrol. JASN 2011, 9, 1631-1641. [CrossRef] [PubMed]

9. Stampfer, M.J.; Sacks, F.M.; Salvini, S.; Willett, W.C.; Hennekens, C.H. A prospective study of cholesterol, apolipoproteins, and the risk of myocardial infarction. N. Engl. J. Med. 1991, 6, 373-381. [CrossRef]

10. Luc, G.; Bard, J.M.; Ferrières, J.; Evans, A.; Amouyel, P.; Arveiler, D.; Fruchart, J.C.; Ducimetière, P. Value of HDL cholesterol, apolipoprotein A-I, lipoprotein A-I, and lipoprotein A-I/A-II in prediction of coronary heart disease: The PRIME Study. Prospective Epidemiological Study of Myocardial Infarction. Arterioscler. Thromb. Vasc. Biol. 2002, 7, 1155-1161. [CrossRef]

11. Puchois, P.; Kandoussi, A.; Fievet, P.; Fourrier, J.L.; Bertrand, M.; Koren, E.; Fruchart, J.C. Apolipoprotein A-I containing lipoproteins in coronary artery disease. Atherosclerosis 1987, 68, 35-40. [CrossRef]

12. Sethi, A.A.; Sampson, M.; Warnick, R.; Muniz, N.; Vaisman, B.; Nordestgaard, B.G.; Tybjaerg-Hansen, A.; Remaley, A.T. High pre-beta1 HDL concentrations and low lecithin: Cholesterol acyltransferase activities are strong positive risk markers for ischemic heart disease and independent of HDL-cholesterol. Clin. Chem. 2010, 7, 1128-1137. [CrossRef] [PubMed]

13. Tashiro, J.; Miyazaki, O.; Nakamura, Y.; Miyazaki, A.; Fukamachi, I.; Bujo, H.; Saito, Y. Plasma pre beta1-HDL level is elevated in unstable angina pectoris. Atherosclerosis 2009, 2, 595-600. [CrossRef] [PubMed]

14. Miida, T.; Miyazaki, O.; Hanyu, O.; Nakamura, Y.; Hirayama, S.; Narita, I.; Gejyo, F.; Ei, I.; Tasaki, K.; Kohda, Y.; et al. LCAT-dependent conversion of prebeta1-HDL into alpha-migrating HDL is severely delayed in hemodialysis patients. J. Am. Soc. Nephrol. 2003, 3, 732-738. [CrossRef]

15. Kontush, A.; Chapman, M.J. Antiatherogenic function of HDL particle subpopulations: Focus on antioxidative activities. Curr. Opin. Lipidol. 2010, 4, 312-318. [CrossRef] [PubMed]

16. Zheng, L.; Nukuna, B.; Brennan, M.L.; Sun, M.; Goormastic, M.; Settle, M.; Schmitt, D.; Fu, X.; Thomson, L.; Fox, P.L.; et al. Apolipoprotein A-I is a selective target for myeloperoxidase-catalyzed oxidation and functional impairment in subjects with cardiovascular disease. J. Clin. Investig. 2004, 4, 529-541. [CrossRef]

17. Huang, Y.; Wu, Z.; Riwanto, M.; Gao, S.; Levison, B.S.; Gu, X.; Fu, X.; Wagner, M.A.; Besler, C.; Gerstenecker, G.; et al. Myeloperoxidase, paraoxonase-1, and HDL form a functional ternary complex. J. Clin. Investig. 2013, 9, 3815-3828. [CrossRef]

18. Matsushita, K.; Van der Velde, M.; Astor, B.C.; Woodward, M.; Levey, A.S.; De Jong, P.E.; Coresh, J.; Gansevoort, R.T. Association of estimated glomerular filtration rate and albuminuria with all-cause and cardiovascular mortality in general population cohorts: A collaborative meta-analysis. Lancet 2010, 9731, 2073-2081.

19. Kuchta, A.; Strzelecki, A.; Ćwiklińska, A.; Gruchała, M.; Zdrojewski, Z.; Kortas-Stempak, B.; Wieczorek, E.; Gliwińska, A.; Dąbkowski, K.; Jankowski, M. HDL subpopulations containing apoA-I without apoA-II (LpA-I) in patients with angiographically proven coronary artery disease. J. Cardiol. 2017, 3, 523-528. [CrossRef]

20. Bu, X.-M.; Niu, D.-M.; Wu, J.; Yuan, Y.-L.; Song, J.-X.; Wang, J.-J. Elevated levels of preß1-high-density lipoprotein are associated with cholesterol ester transfer protein, the presence and severity of coronary artery disease. Lipids Health Dis. 2017, 16, 4. [CrossRef]

21. Chen, Y.; Dong, J.; Chen, X.; Jiang, H.; Bakillah, A.; Zhang, X.; Li, Z.; Yin, J.; Liang, D.; Zou, Y.; et al. Human serum preß1-high density lipoprotein levels are independently and negatively associated with coronary artery diseases. Nutr. Metab. 2016, 13, 36. [CrossRef] [PubMed]

22. Vaziri, N.D.; Liang, K.; Parks, J.S. Down-regulation of hepatic lecithin:cholesterol acyltransferase gene expression in chronic renal failure. Kidney Int. 2001, 6, 2192-2196. [CrossRef] [PubMed]

23. Calabresi, L.; Simonelli, S.; Conca, P.; Busnach, G.; Cabibbe, M.; Gesualdo, L.; Gigante, M.; Penco, S.; Veglia, F.; Franceschini, G. Acquired lecithin:cholesterol acyltransferase deficiency as a major factor in lowering plasma HDL levels in chronic kidney disease. J. Intern. Med. 2015, 5, 552-561. [CrossRef] [PubMed]

24. Asztalos, B.F.; Demissie, S.; Cupples, L.A.; Collins, D.; Cox, C.E.; Horvath, K.V.; Bloomfield, H.E.; Robins, S.J.; Schaefer, E.J. LpA-I, LpA-I:A-II HDL and CHD-risk: The Framingham Offspring Study and the Veterans Affairs HDL Intervention Trial. Atherosclerosis 2006, 1, 59-67. [CrossRef] [PubMed]

25. Ohta, T.; Hattori, S.; Nishiyama, S.; Higashi, A.; Matsuda, I. Quantitative and qualitative changes of apolipoprotein AI-containing lipoproteins in patients on continuous ambulatory peritoneal dialysis. Metabolism 1989, 9, 843-849. [CrossRef] 
26. Durrington, P.N.; Mackness, B.; Mackness, M.I. Paraoxonase and atherosclerosis. Arterioscler. Thromb. Vasc. Biol. 2001, 4, 473-480. [CrossRef]

27. Miljkovic, M.; Stefanovic, A.; Vekic, J.; Zeljkovic, A.; Gojkovic, T.; Simic-Ogrizovic, S.; Bogavac-Stanojevic, N.; Cerne, D.; Ilic, J.; Stefanovic, I.; et al. Activity of paraoxonase 1 (PON1) on HDL2 and HDL3 subclasses in renal disease. Clin. Biochem. 2018, 60, 52-58. [CrossRef]

28. Malle, E.; Marsche, G.; Panzenboeck, U.; Sattler, W. Myeloperoxidase-mediated oxidation of high-density lipoproteins: Fingerprints of newly recognized potential proatherogenic lipoproteins. Arch. Biochem. Biophys. 2006, 2, 245-255. [CrossRef]

29. Teng, N.; Maghzal, G.J.; Talib, J.; Rashid, I.; Lau, A.K.; Stocker, R. The roles of myeloperoxidase in coronary artery disease and its potential implication in plaque rupture. Redox Rep. 2017, 2, 51-73. [CrossRef]

30. Kowalska, K.; Socha, E.; Milnerowicz, H. Review: The role of paraoxonase in cardiovascular diseases. Ann. Clin. Lab. Sci. 2015, 2, 226-233.

31. Morena, M.; Cristol, J.P.; Dantoine, T.; Carbonneau, M.A.; Descomps, B.; Canaud, B. Protective effects of high-density lipoprotein against oxidative stress are impaired in haemodialysis patients. Nephrol. Dial. Transplant. Off. Publ. Eur. Dial. Transpl. Assoc. Eur. Ren. Assoc. 2000, 3, 389-395. [CrossRef]

32. Kuchta, A.; Pacanis, A.; Kortas-Stempak, B.; Cwiklińska, A.; Ziętkiewicz, M.; Renke, M.; Rutkowski, B. Estimation of Oxidative Stress Markers in Chronic Kidney Disease. Kidney Blood Press Res. 2010, 1, 12-19. [CrossRef] [PubMed]

33. Ruan, X.Z.; Varghese, Z.; Moorhead, J.F. An update on the lipid nephrotoxicity hypothesis. Nat. Rev. Nephrol. 2009, 12, 713-721. [CrossRef] [PubMed]

34. Wanner, C.; Krane, V.; Marz, W.; Olschewski, M.; Mann, J.F.; Ruf, G.; Ritz, E. Atorvastatin in patients with type 2 diabetes mellitus undergoing hemodialysis. N. Engl. J. Med. 2005, 3, 238-248. [CrossRef] [PubMed]

35. Krane, V.; Winkler, K.; Drechsler, C.; Lilienthal, J.; Marz, W.; Wanner, C. Effect of atorvastatin on inflammation and outcome in patients with type 2 diabetes mellitus on hemodialysis. Kidney Int. 2008, 11, 1461-1467. [CrossRef] [PubMed]

36. Fellstrom, B.C.; Jardine, A.G.; Schmieder, R.E.; Holdaas, H.; Bannister, K.; Beutler, J.; Chae, D.W.; Chevaile, A.; Cobbe, S.M.; Gronhagen-Riska, C.; et al. Rosuvastatin and cardiovascular events in patients undergoing hemodialysis. N. Engl. J. Med. 2009, 14, 1395-1407. [CrossRef]

37. Asztalos, B.F.; Horvath, K.V.; McNamara, J.R.; Roheim, P.S.; Rubinstein, J.J.; Schaefer, E.J. Comparing the effects of five different statins on the HDL subpopulation profiles of coronary heart disease patients. Atherosclerosis 2002, 2, 361-369. [CrossRef]

38. Franceschini, G.; Calabresi, L.; Colombo, C.; Favari, E.; Bernini, F.; Sirtori, C.R. Effects of fenofibrate and simvastatin on HDL-related biomarkers in low-HDL patients. Atherosclerosis 2007, 2, 385-391. [CrossRef]

39. Tian, L.; Chen, Y.; Li, C.; Zeng, Z.; Xu, Y.; Long, S.; Fu, M. Statin treatment improves plasma lipid levels but not HDL subclass distribution in patients undergoing percutaneous coronary intervention. Lipids. 2013, 2, 127-137. [CrossRef]

40. Miyazaki, O.; Kobayashi, J.; Fukamachi, I.; Miida, T.; Bujo, H.; Saito, Y. A new sandwich enzyme immunoassay for measurement of plasma pre-beta1-HDL levels. J. Lipid Res. 2000, 12, 2083-2088.

41. Nakanishi, M.; Takanami, Y.; Maruyama, T.; Murata, M.; Motohashi, Y.; Nakano, S.; Uchida, K.; Maruyama, C.; Kyotani, S.; Tsushima, M. The ratio of serum paraoxonase/arylesterase activity using an improved assay for arylesterase activity to discriminate PON1(R192) from PON1(Q192). J. Atheroscler. Thromb. 2003, 6, 337-342. [CrossRef]

(C) 2019 by the authors. Licensee MDPI, Basel, Switzerland. This article is an open access article distributed under the terms and conditions of the Creative Commons Attribution (CC BY) license (http:/ / creativecommons.org/licenses/by/4.0/). 